\title{
Multiple myeloma in South Cumbria 1974-80: problems of health analysis in small communities
}

\author{
EG JESSOP* AND SD HORSLEY' \\ From the Department of Community Medicine, South Cumbria Health Authority, Priors Lea, Abbey Road, \\ Barrow in Furness, Cumbria LA $158 \mathrm{JR}$
}

SUMMARY The occurrence of seven cases of multiple myeloma over seven years in a small community 15 miles from a plant reprocessing nuclear fuel caused much local concern. A case control study of 34 confirmed cases in the health district during 1974 to 1980 revealed no excess of known risk factors among the 23 cases for whom informants could be traced. The possible effects of exposure to marine discharges of radioactive material cannot be completely ruled out, but dose estimates make this highly unlikely. Such studies are a necessary response by community physicians to the population they serve but have major practical and theoretical limitations.

Community physicians have a duty to respond to the concerns of the populations they serve, but there are substantial theoretical and practical difficulties in establishing the true meaning of a small increase in the apparent incidence of a disease.

In April 1984, a television programme publicised the apparently high incidence of multiple myeloma on the Island of Walney, which is a strip of land separated by a narrow channel from Barrow in Furness, Cumbria. ${ }^{1}$ Fifteen miles up the coast from Walney at Sellafield is a major installation for reprocessing nuclear fuel, and the thesis of the programme was that radioactive discharges from Sellafield were responsible for the high incidence of myeloma. A complicating factor was the presence of a shipyard in Barrow in Furness which builds nuclear powered submarines. Not surprisingly, this programme caused intense local, and some parliamentary, interest and concern.

Routine statistics from a National Health Service cancer registry, which collects information from hospital discharge summaries and death certificates, showed that between 1974 and 1980 (the most recent year for which complete data were available) seven residents of Walney Island had been registered with multiple myeloma. Using 1981 population data (11 000 residents at census) and standardising for

*Present address: Health Ofices, Turner Road, Colchester, Essex CO4 5JR

†Present address: Oxford Regional Health Authority, Old Road, Headington, Oxford. age and sex against 1977 national rates, ${ }^{2}$ the expected number of cases would have been $2 \cdot 8$ : the Poisson probability of seven or more cases is 0.02 . This is, however, a posterior probability using geographical boundaries of an area already suspected of high incidence.

Because it is difficult to judge what posterior probabilities really mean, myeloma statistics were examined for a geographical zone not defined by the present observation. The obvious choice of zone was the health district in which Walney Island lies, namely, South Cumbria (population 164 000). This choice also fitted in with the wish of South Cumbria's Health Authority for surveillance of the whole of its district of responsibility.

Fifty-nine cases of myeloma were registered in South Cumbria residents during 1974 through 1980 against 49.6 expected $(p=0 \cdot 18)$.

The statistical significance of the excess incidence is therefore debatable, but the public concern aroused was too great simply to ascribe the excess to chance without further study. In other words, the penalty of making a type II error was too high. An investigation was therefore undertaken in an attempt to explain the high registration rate in the health district.

The study was restricted to the 59 cases recorded at the Registry; no further case finding was attempted so as to avoid the bias that arises in comparing data from areas where cases have been fully ascertained with national statistics that are merely routine. 


\section{Method}

The first step was to validate the cancer registry statistics against defined diagnostic criteria. ${ }^{3}$ The diagnosis could be confirmed in only $58 \%$ of registered cases, but this was equally true of a sample of cases from the rest of the north of England. The excess registration rate did not therefore appear to be due to differences in diagnostic practice or in the cancer registration process.

A second phase of the study was then undertaken of the confirmed cases to determine their exposure to known or suspected risk factors for multiple myeloma identified by a literature search. The cases were also analysed for evidence of space-time clustering, which might indicate infective aetiology, and for evidence of familial aggregation.

A case control method was used. Cases were defined as all residents of South Cumbria health district on the cancer registry files for 1974 through 1980 whose clinical case notes contained documentary evidence to satisfy the diagnostic criteria of the South West Oncology Group. ${ }^{4}$ All but two of these had died, and informants (spouse, sib or offspring) were sought for the rest. The case's family doctor was asked to nominate an informant, failing which a visit was made to the last known address of the case.

Controls alive and resident in South Cumbria were randomly selected from the Family Practitioner Committee register, which records all people registered under the National Health Service. Three controls were selected for each case, matched for sex and date of birth (in five year cohorts).

A questionnaire was designed to seek exposure to known or suspected risk factors. A residential history was obtained to detect differences between cases and controls in duration of residence in South Cumbria; and also to distinguish residence in the western coastal strip from elsewhere. This history went back to 1940 . The occupational history included questions about specific exposures and industries implicated by previous research. ${ }^{5}$ Information from informants on war service was found in a pilot study to be too vague, so the occupational history was taken from 1945. Leisure hours spent walking or sailing might increase exposure to airborne radioactive discharges, so a simple question about this was included. The hints of a relation between human haemopoietic cancers and animal leukaemia viruses ${ }^{6,7}$ prompted questions about pet ownership. Medical use of $x$ rays is a major source of radiation exposure and could not be ignored, but quantifying this type of exposure is difficult. The question asked was the number of hospital admissions: this is a crude index of likely exposure to diagnostic radiography, but more refined measures were beyond the scope of this study.

The questionnaire was administered by a lay interviewer. Fieldwork started in June 1984 and was complete by September 1984. The interviewer was aware of the general aim of the survey, as were respondents.

Data for cases and their matched controls were analysed up to the date of diagnosis of the myeloma. Differences between cases and controls were analysed by Fisher's test; odds ratios and confidence limits were estimated by Woolf's method. ${ }^{8}$ The cases were analysed for clustering by Knox's method ${ }^{9}$ using one year as the criterion of closeness in time and residence in the same postcode sector to define closeness in space.

\section{Results}

The clinical notes of four of the 59 registered cases had been lost, and for 21 further cases there was insufficient evidence in the notes to satisfy the diagnostic criteria of the South West Oncology Group. ${ }^{4}$ These criteria are not easily summarised, but, roughly speaking, the 21 excluded cases had no documentation of either monoclonal immunoglobulin production (15) or malignancy (6). Differences between the 34 validated cases and the remainder are shown in table 1.

Two of the 34 cases which satisfied the case definition of the case control study were still alive; informants were traced for 21 other cases. No informant could be found for the remaining 11 cases despite enquiries of the family doctor and at the last known address of the case. Thus information was obtained about $23(68 \%)$ of the 34 valid cases. Known differences between the traced and untraced cases are shown in table 2 . There was markedly less

Table 1 Differences between registered cases meeting and not meeting the diagnostic criteria

\begin{tabular}{lll}
\hline & \multicolumn{1}{l}{ Cases } & \\
\cline { 2 - 3 } & Meeting criteria & Not meeting criteria \\
& $\frac{(n=34)}{n(\%)}$ & $\frac{(n=25)}{n(\%)}$ \\
\hline Male & $20(59)$ & $11(44)$ \\
Born in 1910 or earlier & $19(56)$ & $15(60)$ \\
$\begin{array}{l}\text { Arising in first half of } \\
\text { study period }\end{array}$ & $15(44)$ & $18(72)$ \\
$\begin{array}{l}\text { With last known address } \\
\text { in Barrow }\end{array}$ & $19(56)$ & $15(60)$ \\
\hline
\end{tabular}


Table 2 Known differences between validated cases with and without informant

\begin{tabular}{lll}
\hline & $\begin{array}{l}\text { Informant * } \\
(\mathrm{n}=23)\end{array}$ & $\begin{array}{l}\text { No informant } \\
(\mathrm{n}=11)\end{array}$ \\
\hline $\mathrm{n}(\%)$ & $6(55)$ \\
\hline Male & $14(61)$ & $7(64)$ \\
Born in 1910 or earlier & $12(52)$ & $7(64)$ \\
$\begin{array}{l}\text { Arising in first half of } \\
\text { study period }\end{array}$ & $8(35)$ & $7(64)$ \\
$\begin{array}{l}\text { With last known address } \\
\text { in Barrow }\end{array}$ & $12(52)$ & \\
\hline
\end{tabular}

* Includes two cases still alive.

success in tracing those cases which arose in the first half of the study period.

Fifty-two (75\%) of a possible 69 controls were interviewed. The remaining 17 controls either were not traced at the address recorded on the Family Practitioner Committee register (9 controls) or were considered unsuitable for interview by their family doctor (4), refused (3), or had died (1).

Cases had on average lived eight years longer in Barrow in Furness than controls. Of the cases $48 \%$ had lived in Barrow for more than 20 years compared to $25 \%$ of the controls (Fisher's $p=0.05$ ).

The occupational histories revealed no significant differences between cases and controls (table 3 ). The one case with occupational exposure to radiation had worked in the nuclear shipyard and worn a radiation dosimeter. The two controls included in this category were a man who had worked as a clerk at the nuclear reprocessing plant and a man who had been a builder of nuclear power stations. No case or control had worked with $\mathrm{x}$-ray equipment.

Pet ownership was less common in cases than controls, $70 \%$ of cases and $85 \%$ of controls having owned a cat or dog for more than five years (Fisher's $p=0 \cdot 09$ ). No difference was found between cases and controls in response to the question about leisure activity.

Table 3 Occupational exposure of cases and controls

\begin{tabular}{lllll}
\hline Exposure & $\begin{array}{l}\text { Cases } \\
(\mathrm{n}=23)\end{array}$ & $\begin{array}{l}\text { Controls } \\
(\mathrm{n}=52)\end{array}$ & Odds ratio & $95 \%, \mathrm{CL}$ \\
\hline Radiation & 1 & 2 & $1 \cdot 1$ & $0 \cdot 1,13$ \\
Shipyard & 6 & 9 & $1 \cdot 7$ & $0 \cdot 5,5 \cdot 5$ \\
Farming & 2 & 9 & $0 \cdot 3$ & $0 \cdot 1,2 \cdot 3$ \\
Other $^{*}$ & 4 & 8 & $1 \cdot 2$ & $0 \cdot 3,4 \cdot 3$ \\
\hline
\end{tabular}

* Includes electroplating, smelting, plastics, paper manufacture, and petrochemicals.
Hospital admissions prior to the diagnosis of myeloma were fewer in cases than controls, an average of 1.17 in the former and 1.20 in the latter. One case and four controls had had radiotherapy; the case for a solitary plasmacytoma of rib 15 years before presenting with multiple myeloma and the others for skin complaints (2), thyroid disease (1), and for unknown reasons (1).

No case or control knew any other person with myeloma.

Eight pairs of cases were close in space and time, compared to an expectation of $\mathbf{7 . 6}$ close pairs by Knox's test.

\section{Discussion}

This study has several limitations which are worth considering in detail. Some are almost inevitable in retrospective investigations of disease in small communties and show the practical difficulties of analysing health experiences of small communities and attempting to give a definitive answer. The key problems are:

(1) validating routine statistics; (2) tracing cases or their relatives without unacceptable invasion of privacy; (3) obtaining reliable detailed information about people long since dead; (4) obtaining suitable controls; and (5) achieving adequate statistical power.

(1) The statistics which prompted this study came from a routine data system and needed validating before use. Such validation is best done at the time a case is registered, when supplementary information is readily obtained. This is the normal practice where registers are run by interested clinicians, but the time and expertise needed are often lacking at routine NHS registers. In this study $42 \%$ of the cases registered could not, in retrospect, be validated. Myeloma poses particular problems as definitive diagnosis requires an unpleasant test (bone marrow aspiration) which may not be justified in people in their eighth and ninth decades among whom the disease is commonest; furthermore, the technology for immunoglobulin electrophoresis was not universally available in the 1970s. As a measure of absolute incidence the registry statistics clearly have little value, but they may indicate geographical variations and secular trends, provided like is compared with like. Unfortunately, if a community physician ensures first class data quality and case ascertainment in his own District, the statistics from his District are no longer comparable 
with those from elsewhere. We refrained from case ascertainment so as to avoid this difficulty, since we were investigating not the true incidence of myeloma but a relative excess by comparison with national expectation, and that expectation had been calculated from routine data. The penalty for not seeking out more cases was loss of statistical power in the case control study.

(2) We obtained information on $68 \%$ of the cases, and these were biassed towards the more recent cases. The hospital notes of the untraced cases did not document any occupational radiation exposure, but the quality of recording was poor. Others have used extensive-and intrusive-methods to locate subjects, ${ }^{10}$ but these require substantial resources and are ethically questionable.

(3) Obtaining reliable information was difficult for three reasons. Firstly, it is impossible to validate the questionnaire in an ad hoc retrospective survey. Secondly, myeloma has a latent period of up to 30 years, ${ }^{11}$ and even the best memory is taxed by detailed questions about events that took place long ago, so only crude questions can be asked to assess, say, medical exposure to $x$ rays or occupational exposure to chemicals. Queries about main occupation and address are probably reliable. ${ }^{12}$ Thirdly, there is the use of informants. Others have been forced to use informants in case control studies of fatal diseases,${ }^{13}$ and the reliability of different types of informant has been gauged. ${ }^{14} \mathrm{By}$ accepting only first degree relatives as informants one safeguards the quality of data at the loss of some quantity.

(4) The difficulty in obtaining suitable controls was that almost all of the cases had died. The effects of matching dead cases with live controls are threefold: (1) controls differ from cases in sheer survival, which may indicate a systematic difference in life experience, confounding the one under study; (2) secular change may have occurred to distinguish controls resident in South Cumbria in 1984 from cases resident between 1974 and 1980; (3) there is the bias noted above between first hand and second hand information. In practice, no sampling frame could be found to obtain randomly selected age and sex matched controls of 1974-80 South Cumbria residents, so the use of live controls was forced. Gordis has discussed the problems of matching dead cases with live controls. ${ }^{15}$
(5) The chief limitation on study power was the rarity of exposure to some risk factors in the control population. ${ }^{16}$

This is reflected in the confidence limits, which are wider for exposure at work to radiation than for work in the shipyard.

A second limit on study power is the small number of cases for study, a constraint of history. The number of cases could have been increased by widening the case definition, which included only cases satisfying strict diagnostic criteria, resident in the health district, registered between 1974 and 1980 . This could have been done in three ways. Firstly, looser diagnostic criteria could have been used. The pros and cons of a loose case definition have been analysed theoretically, ${ }^{17}$ but the extensive differential diagnosis of multiple myeloma ${ }^{18}$ dictates a strict case definition if confusion is to be avoided. Secondly, the geographical limits could have been extended, but only at the cost of missing an aetiological agent acting in a small area. Thirdly, the time period could have been extended. As with geographical extension this may blur the margin of a cluster. The study included the most up to date data (1980) available when the study began; extension to before 1974 seemed unwise because of the greater diagnostic uncertainty ten years ago $^{19}$ and the smaller chance of tracing informants.

These difficulties of study size and data quality have been encountered in other? retrospective studies of local health issues. ${ }^{20-22}$ It should also be noted that even classic papers on myeloma are often based on small numbers of cases; for example, the risk estimates for radiation dose from atomic bomb survivors are based on five cases, with confidence limits almost as wide as those in the present study. ${ }^{11,23}$

The final practical constraint on the study design was that both the interviewer and the respondents knew the general aim of the study. Local awareness of the relation between radioactivity and blood cancers is high, and anyway the need to seek familial clusters forced a direct question about multiple myeloma.

How should one interpret the one significant difference found between cases and controls, namely, duration of residence in Barrow? Barrow constitutes the Irish Sea coast of the district, and almost all Barrow residences are within 10 kilometres of the sea. They are therefore exposed to marine 
discharges of radioactive material from the nuclear reprocessing plant at Sellafield. ${ }^{24}$ The pathway of this exposure is inhalation of sea spray. The annual average dose is estimated ${ }^{24}$ as 2 micro-Sievert; this compares with a natural background dose of 2000 micro-Sievert. It seems unlikely that an extra $0 \cdot 1 \%$ radiation dose would account for the excess incidence of myeloma, but this cannot be completely ruled out if unusual threshold effects occur in induction of myeloma by radiation.

Analysis by Knox's method showed no clustering in time and space, such as would be expected if case to case transmission of the disease or exposure to a common aetiological agent were responsible. The definitions of closeness in time and space are of course entirely arbitrary. Knox used distance as the crow flies to define closeness. ${ }^{9}$ This blurs the distinctness of places which though physically close are separate communities (eg, separated by a waterway), and postcode sectors were preferred in this study as a measure of social closeness.

No evidence of familial aggregation was found. Family pedigrees of paraproteinaemia have been discribed, ${ }^{25,26}$ and a single affected family could noticeably elevate the incidence of a rare tumour in a small community.

It would be extraordinary if the incidence of myeloma were uniform across the country. Patches of high incidence have been reported in Aberdeen $^{27}$ and Fylde; ${ }^{28}$ doubtless other peaks could be found if sought. No abnormal exposure to risk factors have been found to account for the high incidence of myeloma in South Cumbria from 1974 to 1980 , and the most likely explanation is that this was a random occurrence which will not persist or recur. This conclusion was acceptable to the local health authority and the local press, but not to an environmental pressure group, who have demanded a further investigation of all cases from 1960 onwards, analysed by electoral ward. A similar fate befell the 'qualified reassurance' offered by an enquiry ${ }^{29}$ (also stimulated by a television documentary) into cancer incidence in the immediate neighbourhood of Sellafield. It is likely that the case control study recommended by this enquiry will encounter most of the problems discussed above.

This study illustrates some of the difficulties experienced in attempting to answer justified concerns of local inhabitants about variations in the incidence of rare diseases. The public does not want woolly answers expressed in terms of probabilities. We believe that statisticians and academic departments of community medicine should address the conceptual and methodological problems of small area statistics to assist their colleagues serving communities which are increasingly concerned about local health issues.

We are grateful to Dr DP Forster for encouragement and advice and to Mrs MJ Bagenal for skilful fieldwork.

The study was supported by a grant from the National Radiological Protection Board.

\section{References}

${ }^{1}$ Anon. The Daily Telegraph world atlas. London: Collins, 1973,8

${ }^{2}$ Office of Population Censuses and Surveys. Cancer statistics registrations. Series MB1 number 8 . London: HMSO 1982.

${ }^{3}$ Jessop EG, Horsley SD. Validity of cancer statistics for multiple myeloma for South Cumbria. Br Med J 1984 289: 84 .

4 Durie BGM, Salmon SE. Multiple myeloma, macroglobulinaemia and monoclonal gammopathies. In: Hoffbrand AV, Brain MC, Hirsh J, eds. Recent advances in haematology. New York: Churchill Livingstone, 1977: 243-61.

s Blattner WA. Multiple myeloma and macroglobulinaemia. In: Schottenfeld D, Fraumeni JR, eds. Cancer epidemiology and prevention. Philadelphia: WB Saunders 1982, 795-813.

${ }^{6}$ Blattner WA, et al. The human Type C retrovirus, HTLV, in Blacks from the Caribbean region, and relationship to adult T cell leukaemia/lymphoma. Int J Cancer 1982; 30: $257-64$.

${ }^{7}$ Henry LW. Multiple myeloma in a mink handler following exposure to Aleutian disease. Cancer 1979; 44: 273-5.

${ }^{8}$ Schlesselman JJ. Case control studies. New York: OUP 1982, 176-7.

${ }^{9}$ Knox G. Epidemiology of childhood leukaemia in Northumberland and Durham. Br J Prev Soc Med 1964; 18: $17-24$.

${ }^{10}$ Abbatt JD, Newcombe HB. Personal privacy concerns threaten epidemiology. Community Med 1983; 5: $321-6$.

${ }^{11}$ Ichimaru M, Ishimaru T, Mikami M, Matsunaga $M$. Multiple myeloma among atomic bomb survivors in Hiroshima and Nagasaki, 1950-76: relationship to radiation dose absorbed by marrow. $J$ Natl Cancer Inst 1982; 69: 323-8.

${ }^{12}$ Baumgarten M, Siemiatycki J, Gibbs GM. Validity of work histories obtained by interview for epidemiologic purposes. Am J Epidemiol 1983; 118: 583-91.

${ }^{13}$ Bobowick AR, Brody JA, Mattews MR, Roos R, Gajdusek DC. Creutzfeld-Jacob disease: a case control study. Am J Epidemiol 1973; 98: 381-94.

${ }^{14}$ Pickle LW, Brown LM, Blot WJ. Information available from surrogate respondents in case-control interview studies. Am J Epidemiol 1983; 118: 99-108. 
${ }^{15}$ Gordis L. Should dead cases be matched to dead controls? Am J Epidemiol 1982; 115: 1-5.

${ }^{16}$ Crombie IK. The limitations of case control studies in the detection of environmental carcinogens. J Epidemiol Community Health 1981; 35: 281-7.

${ }^{17}$ Rosenbaum PR. Case definition and power in case control studies. Stat Med 1984; 3: 27-34.

${ }^{18}$ Bergsagel DE. Plasma cell myeloma. In: Williams WJ, Bertler E, Erslev AJ, Rundles RW. Hematology, 2nd ed. New York: McGraw Hill 1978, 1111-2.

${ }^{19}$ Velez R, Beral V, Cuzick J. Increasing trends of multiple myeloma mortality in England and Wales 1950-79: are the changes real? J Natl Cancer Inst 1982; 69: 387-92.

${ }^{20}$ West RR, Willis JD. An example of medical audit under political pressure. Int J Epidemiol 1983; 12: 482-6.

${ }^{21}$ Hearey $C D$, et al. Investigation of a cluster of anencephaly and spina bifida. Am J Epidemiol 1984; 120: 559-64.

${ }^{22}$ Paneth N, Kiely M, Hegyi T, Hiatt IM. Investigation of a temporal cluster of left sided congenital heart disease. $J$ Epidemiol Community Health 1984; 38: 340-4.

${ }^{23}$ Cuzick J. Radiation induced myelomatosis. N Engl J Med 1981; 304: 204-10.
${ }^{24}$ Linsley GS, Dionion J, Simmonds JR, Burgess J. An assessment of the radiation exposure of members of the public in West Cumbria as a result of the discharges from BNFL Sellafield. NRPB-R170. Chilton: National Radiological Protection Board 1984.

${ }^{25}$ Maldonado JE, Kyle RA. Familial myeloma. Am J Med 1974; 57: 875-84.

${ }^{26}$ Meijers KAE, Leeuw B, Voormolen-Kalova M. The multiple occurrence of myeloma and asymptomatic paraproteinaemia within one family. Clin Exp Immunol 1972; 12: 185-93.

${ }^{27}$ Dawson AA, Ogston D. High incidence of myelomatosis in north-east Scotland. Scot Med J 1973; 18: 75-7.

${ }^{28}$ Flanagan NG, Harry DS, Kozlowski T, Sorahan T. Multiple myeloma on the Fylde coast. Br Med J 1984; 289: 1075.

${ }^{29}$ Independent Advisory Group (chairman: Sir Douglas Black). Investigation of the possible increased incidence of cancer in West Cumbria. London: HMSO, 1984. 